\title{
Strategies for high current densities in non-fullerene acceptors based organic solar cells
}

\section{Xin Song, Joel Troughton, Nicola Gasparini, Derya Baran}

Xin Song, Joel Troughton, Nicola Gasparini, Derya Baran, "Strategies for high current densities in non-fullerene acceptors based organic solar cells," Proc. SPIE 10687, Organic Electronics and Photonics: Fundamentals and Devices, 106870I (22 May 2018); doi: 10.1117/12.2315945 


\title{
Strategies for High Current Densities in Non-Fullerene Acceptors based
}

\author{
Organic Solar Cells
}

\author{
Xin Song, Joel Troughton, Nicola Gasparini, Derya Baran* \\ Division of Physical Sciences and Engineering, KAUST Solar Center (KSC), King Abdullah \\ University of Science and Technology (KAUST), Thuwal, Saudi Arabia
}

\begin{abstract}
Here, we report the strategies to increase the photon harvesting in single junction organic photovoltaics by band gap engineering. Low band-gap non-fulllerene small molecule acceptors yield remarkable short-circuit current (26.6 $\mathrm{mA} / \mathrm{cm}^{2}$ ) which comparable to existing high efficiency photovoltaic technologies.
\end{abstract}

\section{INTRODUCTION}

High photocurrent density $\left(J_{s c}\right)$ is a crucial parameter for champion efficiencies in organic solar cells (OSCs). In the bulk heterojunction (BHJ) configuration, consisting of donor and fullerene acceptor materials intimately mixed together, achieving high $J_{s c}$ (over $20 \mathrm{~mA} / \mathrm{cm}^{2}$ ) was challenging. In fact, the low absorption coefficient as well as the limited absorption window of the conjugated polymer donor were the limiting factors for high efficiency solar devices. In order to overcome such limitation, scientists firstly considered to introduce a strong electron push-pull building block to extend the absorption range from the ultraviolet and visible to the near-infrared region (700 nm-1000 nm). For example, Yan and coworkers reported a series of polythiophene based polymers with a strong absorption form $300 \mathrm{~nm}$ to $800 \mathrm{~nm}$. The corresponding devices yielded the current density over $20 \mathrm{~mA} / \mathrm{cm}^{2}$. ${ }^{1}$ State-of-the-art materials are the diketopyrrolopyrrole (DPP) based polymers, which can get the absorption range approximately to $900 \mathrm{~nm}$. Based on the device engineering, $23 \mathrm{~mA} / \mathrm{cm}^{2}$ has been reported in the DPP system. ${ }^{2,3}$ However, the inherent drawbacks (low absorption coefficient and absorption range) of the fullerene derivate acceptors limited the improvement room for boosting the current density. Fortunately, the non-fullerene acceptors (NFA) has been put forward and made a great success recently, which obtained efficiencies over $13 \%$ together with a current density of $20 \mathrm{~mA} / \mathrm{cm}^{2}$ in the literature. In comparison with the fullerene acceptors, the success of NFA can be attributed to several reasons:

(i) By the strong electron push-pull interaction between the electron withdrawing groups to the electron donating core, it is possible to achieve a narrow optical bandgap and enhanced $\pi$ - $\pi$ coherence length.

(ii) By the incorporation of the strong rigid building block, the molecules would possess a small steric hindrance and a large overlap between the highest occupied molecular orbital (HOMO) and lowest unoccupied molecular orbital (LUMO) of the NFA, which leads to a greater oscillator strength and therefore a stronger absorption of light.

(iii) By coupling with fluorine or chlorine atoms in the end group, due to the high electronegativity and strong intramolecular effect of these atoms, the electron cloud will be much more delocalized in the small molecule, which would cause the significant redshift in comparison with the small molecule without the $\mathrm{F}$ or $\mathrm{Cl}$ incorporation. 
a

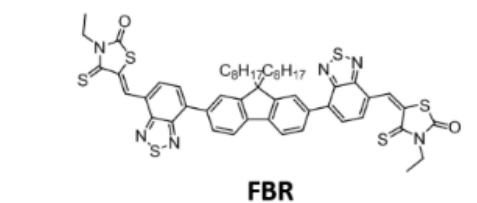

FBR

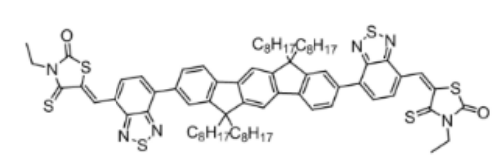

IDFBR

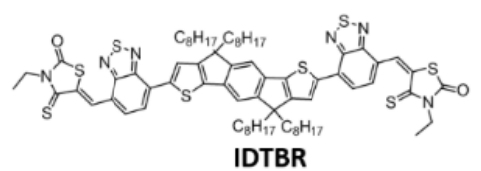

IDTBR
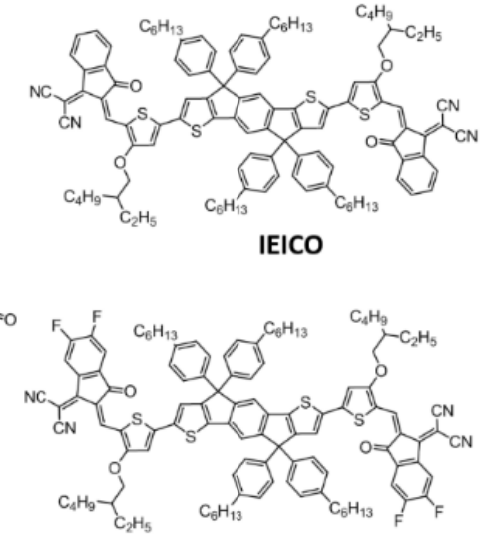

IEICO-4F b

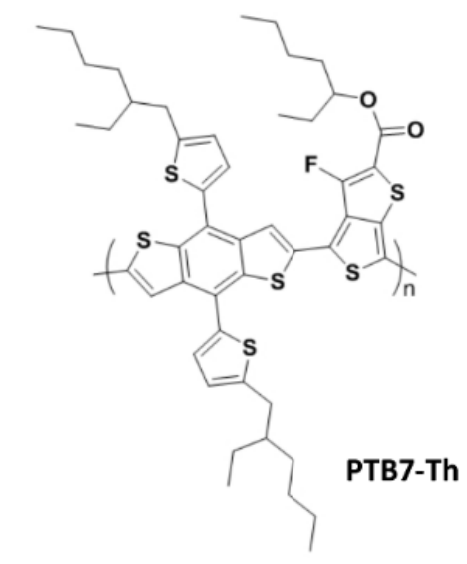

Figure 1: The chemical structures of the non-fullerene acceptors (a) and PTB7-Th (b).

\section{RESULTS and DISCUSSION}

In this work, we selected five non-fullerene acceptors, which are abbreviated as FBR, IDFBR, IDTBR, IEICO, IEICO-4F, respectively and polymer donor PTB7-Th ( or PBDTTT-EFT) (Figure 1). The absorption spectra of these NFAs can be effectively tuned by manipulating the intramolecular electron push-pulling effect while keeping their key features (Acceptor-donor-acceptor molecular geometry) to ensure the strong molecular interaction. On one hand, the broad absorption range is essential to obtain high photocurrent response. As shown in Figure 2a, because of the stronger ICT effect and planar building block from fluorene, indenofluorene (IDF) to rigid indacenodithiophene (IDT) of the corresponding FBR, IDFBR and IDTBR, the absorption onsets of these NFAs were gradually shifted from 586 $\mathrm{nm}, 619 \mathrm{~nm}$ to $767 \mathrm{~nm}$, respectively. ${ }^{5-7}$ Besides, by inserting a spacer (alkoxy thiophene) to enhance the ICT effect and electron delocalization (IEICO), the absorption onset was further bathochromic-shifted to $926 \mathrm{~nm}$. Further introducing $\mathrm{F}$ atom in the peripheral units, the absorption onset of IEICO was shifted up to $1000 \mathrm{~nm}$ (IEICO-4F). On the other hand, the absorption coefficient is another important parameter to obtain high photocurrent, the maximum absorption coefficient of FBR, IDFBR and IDTBR was illustrated to have a general improvement form $4.5 \times 10^{4} \mathrm{M}^{-}$ ${ }^{1} \mathrm{~cm}^{-1}, 7.9 \times 10^{4} \mathrm{M}^{-1} \mathrm{~cm}^{-1}$ and $1.1 \times 10^{5} \mathrm{M}^{-1} \mathrm{~cm}^{-1}$, respectively. These results show that absorption coefficient have a contribution effect to the current densities (Table 1). ${ }^{8}$ For IEICO and IECIO-4F, the values of maximum absorption coefficient was enhanced from $8.2 \times 10^{4} \mathrm{M}^{-1} \mathrm{~cm}^{-1}$ to $9.0 \times 10^{4} \mathrm{M}^{-1} \mathrm{~cm}^{-1}$. We assume that the complementary absorption plays another vital role to obtain high currents because of the full utilization of solar irradiance spectra (shown from Figure 2a). ${ }^{5}$ 
In addition to the absorption range and strength of the NFA, the complementary absorption of the conjugated polymer donor and optimal blend morphology also play a crucial role of the high photocurrent. Recently, our group utilize a well-known middle-low bandgap polymer donor (PTB7-Th) blended with a narrow band gap nonfullerene acceptor (IEICO-4F) as the active layer, which possesses an absorption range from $300 \mathrm{~nm}$ to $1000 \mathrm{~nm}$ (Figure 2a). ${ }^{9}$ Interestingly, when we fabricated devices with 1-chloronaphthalene $(\mathrm{CN})$ as the solvent additive, the optimization of the photoactive layer yields a short-circuit current density value over $26 \mathrm{~mA} / \mathrm{cm}^{2}$. (Figure $2 \mathrm{~b}$ ) (Table 1) The morphology characterizations elucidate that the origin of this high photocurrent is mainly the increased $\pi-\pi$ coherence length of the acceptor, the domain spacing, as well as the mean-square composition variation of the blend.
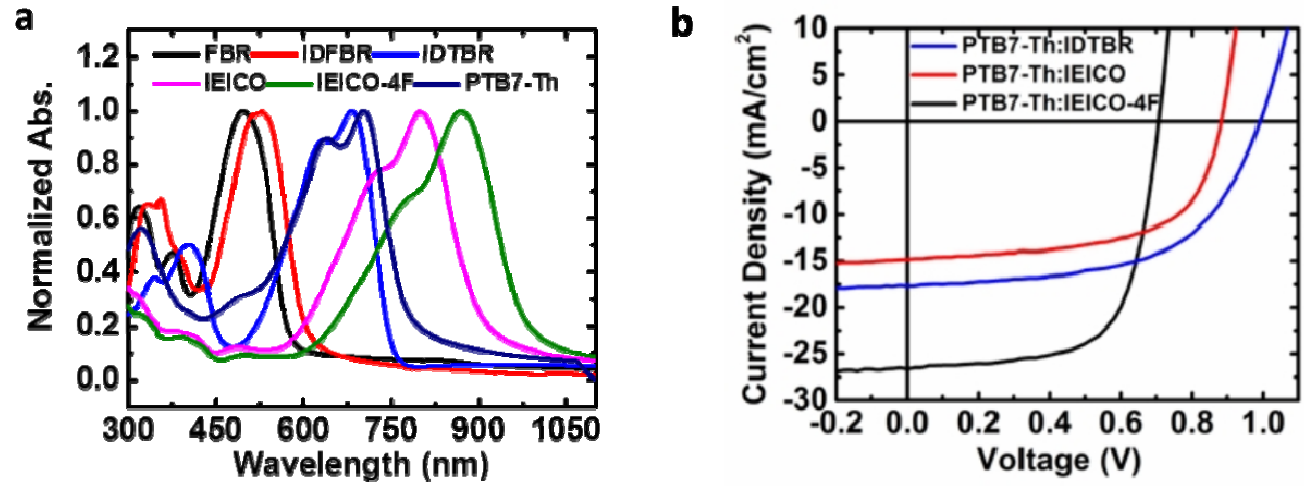

Figure 2: (a) Normalized absorption curves of the NFA materials and J-V curves of the champion devices of PTB7Th:IDTBR; PTB7-Th:IEICO and PTB7-Th:IEICO-4F, respectively.

Table 1 the device parameter of the solar cells with different NFAs

\begin{tabular}{lllll}
\hline Blend Film & $\begin{array}{l}\mathrm{J}_{\mathrm{sc}} \\
\left(\mathrm{mA} / \mathrm{cm}^{2}\right)\end{array}$ & $\begin{array}{l}\mathrm{V}_{\mathrm{oc}} \\
(\mathrm{mV})\end{array}$ & $\begin{array}{l}\mathrm{FF} \\
(\%)\end{array}$ & $\begin{array}{l}\text { PCE } \\
(\%)\end{array}$ \\
\hline PTB7-Th:IDTBR & 17.7 & 992 & 57.3 & 10.1 \\
PTB7-Th:IEICO & 14.8 & 883 & 61.2 & 7.95 \\
PTB7-Th:IEICO-4F & 26.6 & 707 & 66.0 & 12.4 \\
\hline
\end{tabular}


Table 2 Summary of recent works about current density, optical bandgap and device performance in solutionprocessable solar cells

\begin{tabular}{llll}
\hline $\begin{array}{l}\text { Current Density } \\
\left(\mathrm{mA} / \mathrm{cm}^{2}\right)\end{array}$ & Optical bandgap & $\begin{array}{l}\text { PCE } \\
(\%)\end{array}$ & Reference \\
\hline 20.0 & 1.38 (donor) & 9.40 & $10.1002 /$ adma.201501132 \\
20.3 & 1.66 (NFA acceptor) & 10.9 & $10.1021 /$ acs.chemmater.7b01650 \\
22.8 & 1.24 (NFA acceptor) & 10.0 & $10.1002 /$ anie.201610944 \\
24.9 & $\begin{array}{l}1.55 \text { (lead based } \\
\text { perovskite) } \\
1.24(\text { tin lead mixed } \\
\text { perovskite) }\end{array}$ & 14.8 & $10.1038 /$ nenergy.2016.177 \\
26.8 & 1.10 (quantum dots) & 9.8 & $10.1126 /$ science.aaf 9717 \\
30.6 & & $10.1002 /$ adma.201700749 \\
\hline
\end{tabular}

In conclusion, we highlight that the rational design strategies and optimization blend morphology are the two main important factors to obtain high photocurrent. We hypothesized that with broad absorption range (300 nm to $1000 \mathrm{~nm}$ ) and excellent blend morphology, the current density of organic solar cells can have a great potential to compete with other types of solution-processed solar cells, such as perovskite or quantum dot devices. (Summarized in Table 2)

derya.baran@kaust.edu.sa, phone: +966544701242, kaust.omegalab.edu.sa 
References:

(1) Zhao, J.; Li, Y.; Yang, G.; Jiang, K.; Lin, H.; Ade, H.; Ma, W.; Yan, H. Efficient Organic Solar Cells Processed from Hydrocarbon Solvents. Nature Energy. 2016, 27.

(2) Li, W.; Hendriks, K. H.; Wienk, M. M.; Janssen, R. A. J. Diketopyrrolopyrrole Polymers for Organic Solar Cells. Acc. Chem. Res. 2016, 49 (1), 78-85.

(3) Oklem, G.; Song, X.; Toppare, L.; Baran, D.; Gunbas, G. New NIR Absorbing DPP-Based Polymer for Thick Organic Solar Cells. J. Mater. Chem. C 2018, 6 (12), 2957-2961.

(4) Zhao, W.; Li, S.; Yao, H.; Zhang, S.; Zhang, Y.; Yang, B.; Hou, J. Molecular Optimization Enables over 13\% Efficiency in Organic Solar Cells. J. Am. Chem. Soc. 2017, 139 (21), 7148-7151.

(5) Song, X.; Gasparini, N.; Baran, D. The Influence of Solvent Additive on Polymer Solar Cells Employing Fullerene and Non-Fullerene Acceptors. Adv. Electron. Mater. 2017, 1700358.

(6) Nielsen, C. B.; Holliday, S.; Chen, H.-Y.; Cryer, S. J.; McCulloch, I. Non-Fullerene Electron Acceptors for Use in Organic Solar Cells. Acc. Chem. Res. 2015, 48 (11), 2803-2812.

(7) Gasparini, N.; Salvador, M.; Strohm, S.; Heumueller, T.; Levchuk, I.; Wadsworth, A.; Bannock, J. H.; de Mello, J. C.; Egelhaaf, H.-J.; Baran, D.; McCulloch, I.; Brabec, C. J. Burn-in Free Nonfullerene-Based Organic Solar Cells. Adv. Energy Mater. 2017, 7 (19), 1700770.

(8) Holliday, S.; Ashraf, R. S.; Wadsworth, A.; Baran, D.; Yousaf, S. A.; Nielsen, C. B.; Tan, C.-H.; Dimitrov, S. D.; Shang, Z.; Gasparini, N.; Alamoudi, M.; Laquai, F.; Brabec, C. J.; Salleo, A.; Durrant, J. R.; McCulloch, I. High-Efficiency and Air-Stable P3HT-Based Polymer Solar Cells with a New Non-Fullerene Acceptor. Nat. Commun. 2016, 7, 11585.

(9) Song, X.; Gasparini, N.; Ye, L.; Yao, H.; Hou, J.; Ade, H.; Baran, D. Controlling Blend Morphology for Ultrahigh Current Density in Nonfullerene Acceptor-Based Organic Solar Cells. ACS Energy Lett. 2018, 3 (3), 669-676. 